\title{
Performance Evaluation in Nonprofit Organization
}

\author{
Wan Taiyong \\ School of Public Management, Yunnan University of Finance and Economics, \\ Kunming, P.R.China, 650221 \\ (E-mail: 783224799@qq.com)
}

\begin{abstract}
Nonprofit organizations have significant effects and functions in our society. It is an important part of social system. The performance evaluation of nonprofit organizations is essential in order to help the organizations developed well. With the development of performance appraisal, evaluating performance in nonprofit organization became a basic part of it. Researches fund that performance evaluation in nonprofit organization combination method of quantitative, qualitative, and process. This article based on the situations of nonprofit organization in China, shows the standards and methods in performance evaluation in nonprofit organizations, analyzes the problems and difficulties during the appraisal, and find out some measures to deal with the problems.
\end{abstract}

Keywords: Nonprofit Organization, Performance Appraisal, Problems and Difficulties, Measures

\section{Introduction}

From a system's perspective, the social system consists of profit organizations, nonprofit organizations and governments. But the management of enterprises and governments is different from nonprofit organizations. Due to the internal and external factors (e.g. organization's missions and objectives) of the nonprofit organization are particular. The performance evaluation in nonprofit organizations is much more difficult than in governments, especially in China. Therefore, the researches of performance evaluation in nonprofit organization are essential and significant in order to promote the normal operation, the efficiency and ability to work, the acceptance of public and visibility of nonprofit organization in our country.

\section{Theories of performance evaluation in Nonprofit organizations}

The theories still under the exploit to find a effective way of performance evaluation in nonprofit organization. According to the research of Robert D. Herman and David O. Renz, NPO effectiveness is (1) always comparative, (2) multidimensional, (3) related to board effectiveness (but how is not clear), (4) related to the use of correct management practices but not in any simple "best practices" way, and (5) a social construction. Furthermore, (6) it is unlikely that there are any universally applicable best practices that can be prescribed for all NPO boards and management, (7)organizational responsiveness is a useful organizational-level effectiveness measure, (8) distinguishing among types of NPOs is important and useful, and (9) level of analysis makes a difference in researching and understanding effectiveness.[1] There are several standards and methods to evaluate nonprofit organizations even though there are limitations of them.

\subsection{Standards of performance evaluation}

2.1.1.3E Assessment Method is referred to Economy, Efficiency, and Effectiveness and added Equity to 4E because of the objectives (e.g. equality, democracy) of government and nonprofit organization in society. This kind of evaluation will improve the performance in nonprofit organization.

2.1.2.3D Assessment Method is referred to Diagnosis, Design and Development. Focus on enhance the capacity building, continuous learning and improvement of nonprofit organizations through performance evaluation. 
2.1.3.APC Method is a performance evaluation index system proposed by Tsinghua University associate professor Deng Guosheng.[2] Combine the characteristics of nonprofit organization in China and the results of investigations, analyze the weaknesses of 3E and 3D theory as well as the "Customer Satisfaction" theory to practical application in China. Propose Accountability, Performance and Capacity to evaluate the nonprofit organizations.

2.1.4.Outcome-Based Evaluation: Martin and Kettner use this method to evaluate Efficiency, Quality, and Effectiveness.

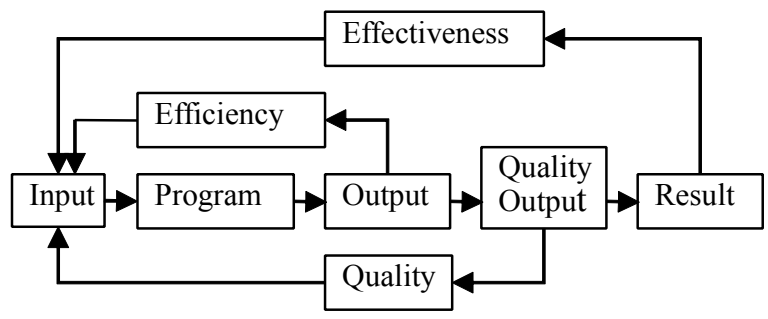

Fig. 1 Performance Measurement System Model

Source: Martin and Kettner, 1996

2.1.5 Balanced Score Card: Paul Niven proposed balanced score card for public institution in 2003 provided an entire method for performance evaluation of nonprofit organization.

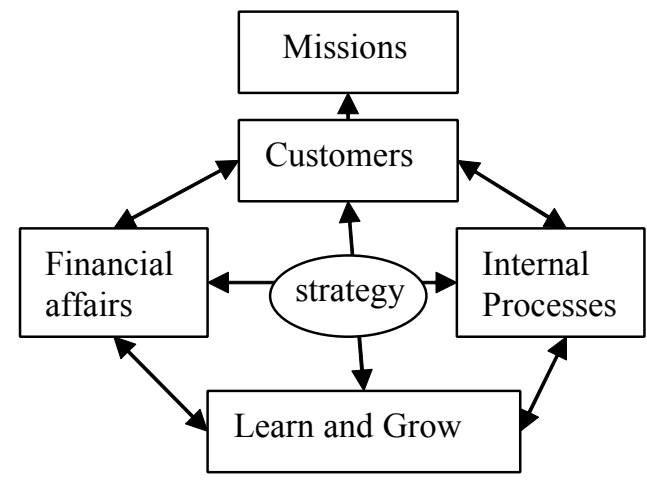

Fig. 2 Balanced Score Card of Nonprofit Organization

Source: Pual R. Niven, 2003

The development of performance evaluation standards for nonprofit organization reflects two characteristics: first majority standards of the quantitative evaluation developed to combination quantitative and qualitative; secondly from focusing on the evaluation of the results to take the results and processes into account.

\subsection{Methods of performance evaluation}

\subsubsection{Benchmarking}

Benchmarking is a normal method for nonprofit organization to evaluate their performances.

\subsubsection{Total Quality Management}

Total Quality Management is a full participation using variety of scientific methods to improve the organization's management and services. It is a management concepts, systems and methods to gain customer satisfactions through high-quality and continuous improvement of products and services.[3]

\subsubsection{Rating Method}

Rating Method is the easiest and usual method to evaluate performance.

2.2.4 Management

Management by Objective is one of the popular methods for performance evaluation.

\subsubsection{Other Methods}

Critical Incident Technique, All-round Performance Assessment, DEA Analysis Methods[4], PAQS (Program Accountability Quality Scale)[5],AIMES (Annual Impact Monitoring and Evaluation Program)[6] etc.

\subsection{Limitations of Theories}

People started to realize it is essential to use appraisal or other manage tools to improve and promote the development of nonprofit organization since 1990s. But there are still limitations and restrictions of the theories in evaluate nonprofit organizations.

2.3.1 Limitations of 3E Assessment Theory $3 \mathrm{E}$ assessment is first use in the government's performance evaluation and then extended to nonprofit sectors. Focusing on the impact of evaluation theory and concerned with the assessment of economy, efficiency and effectiveness in projects while ignoring the implementation of the project, capacity building and accountability requirements of the organization. As a result, the project can get some outputs, but the nonprofit organization itself would be lack of abilities for sustainable development and even lead to some bad phenomenon like the abuse of resources, corruption.

2.3.2 Limitations of 3D Assessment Theory $3 \mathrm{D}$ evaluation theory has a greater role to enhance the organizational capacity of nonprofit organizations, but has limitations 
in improving efficiency and public confidence of the organization. It is difficult to quantify the qualitative aspects of the assessment and to compare between different organizations. Therefore, it cannot be implemented reward and punishment according to the results of the evaluation.

\section{Problems and difficulties in appraisal}

Although the theories and methods of nonprofit organizations are various, especially the evaluation application system has become mature abroad. The performance evaluations of nonprofit organizations in China have been carried out gradually and have achieved some successes. But there are some defects in the performance evaluation.

\subsection{The control of governments}

The governments control over nonprofit organization is too strict, so it affecting the independence of the performance evaluation. The lacking of independence leads nonprofit organization in China to become an adjunct of the business group. Causing unfair and subjective on the evaluation purposed, processes and results which weakening the role of performance evaluation in nonprofit organization.

\subsection{Lack of an independent personnel authority}

A large part of the cadres of nonprofit sectors in China, mainly in charge of the department of nominated by the head of the organization. (Tab. 1)This makes the nonprofit organization to the lack of independent right to the appointment, removal, and weakened the function of performance evaluation.

\begin{tabular}{|c|c|}
\hline Percentage & Sources \\
\hline $23.3 \%$ & $\begin{array}{c}\text { Nominated by manager and } \\
\text { appointed by the competent } \\
\text { authorities. }\end{array}$ \\
\hline $38.5 \%$ & $\begin{array}{c}\text { Appointed by the competent } \\
\text { authorities. }\end{array}$ \\
\hline $8.6 \%$ & Without special rules. \\
\hline
\end{tabular}

Tab. 1 Sources of Managers in Nonprofit Organizations [7]

\subsection{The financial difficulties}

The financial difficulties caused by the lack of a solid material basis for performance evaluation. The funding sources of nonprofit organization including: government subsidies, private donations, service charges and foreign aid (Tab. 2). In China, the donation environment is serious. Therefore, most of nonprofit organizations are lack of funds.

\begin{tabular}{|c|c|}
\hline Percentage & Sources of Income \\
\hline $\begin{array}{c}\text { More than } \\
70 \%\end{array}$ & $\begin{array}{c}\text { Financial grants, subsidies } \\
\text { and membership fees }\end{array}$ \\
\hline $6 \%$ & Operating income \\
\hline
\end{tabular}

Tab. 2 Sources of Income of Nonprofit Organizations [7]

\subsection{Lack of own capacity}

Nonprofit organizations started late in China, due to the lack of financing capacity, lack of oversight mechanisms, the information systems to adapt to the performance assessment process is not perfect and the lack of professional evaluation staffs. The performance appraisal is difficult to carry out.

\subsection{The Problems of Evaluation System}

Performance evaluation of nonprofit organizations in China is new, so it still not formed a standardized and systematic evaluation system. The problems of the evaluation system are the single assessment method, the sidedness of the evaluation standards and the incomplete of the measures for evaluation.

\section{Measures to solve the problems in performance appraisal}

Although there are various problems of the performance evaluation in nonprofit organizations, measures to solve the problems are multiple and valid. The measures are based on three fields: the government to broaden the regulations and restrictions as well as given the nonprofit organization independent or personnel management, intermediary agency should be built based on profession to promote the works of nonprofit organization and the 
nonprofit organization should strengthen itself .

\subsection{Measures for government}

The government should broaden the regulations and restrictions of nonprofit organization to provide a relatively policy and legal environment. Meanwhile adopted a positive attitude of their development and provide preferential policies for them. In terms of financial, human and other aspects to full support and coordination for the development of nonprofit organizations as well as provide good policy laws and regulations.

The government should give the nonprofit organization independent of personnel management, so that the performance appraisal results can be practical and effective. General mobilization the enthusiasm and initiative of cadres and employees, and also provide a broad space for the performance evaluation of the nonprofit organizations.

\subsection{Establish a professional institution for performance appraisal}

According the practical experiences of the world, not only to establish a set of performance evaluation system within the nonprofit organization is needed, but the performance evaluation system in the legislation and the audit department to implementation and supervision also needed. The process operating of nonprofit organization is plagued by bureaucracy corruption and other problems. At the same time, different nonprofit organization has different understanding of the public interest and performance evaluation. So the oversight of nonprofit organization to implement is necessary.

Established a professional assessment agency has a correct understanding of civil society and citizenship. An agency can promote and supervise the works of nonprofit organization to give appropriate organizational guarantee.

\subsection{Measures of nonprofit organization}

The nonprofit organization should strengthen itself to provide a good organizational guarantee for the performance appraisal. Established a complete information system and make full use of computers and modern communication technologies, training professional evaluators to adapt to the needs of performance assessment.

Enhance openness and transparency of the performance appraisal of nonprofit organizations.

The purpose of nonprofit organizations is to provide public goods and services. Their object is the public, so the satisfaction of the public is a performance evaluation is an important and main standard of the performance evaluation. Helping the public to have a more in-depth and a more detailed understanding of the work in nonprofit organization though released the performance of all aspects to the public. This will help citizens to better supervise and participate in the performance evaluation. Thereby increasing the level of performance management, and promote the work of nonprofit organization.

\section{Conclusion}

Nonprofit organizations have significant effects and functions in our society. From a system's perspective, the social system consists of profit organizations, nonprofit organizations and governments. Researches fund that performance evaluation in nonprofit organization combination method of quantitative, qualitative, and process. The performance evaluations of nonprofit organizations in China have been carried out gradually and have achieved some successes. This article is based on the connotation and the concept of nonprofit organizations, reviews the performance assessment criteria, standards and methods of nonprofit organizations then analyzed the change of the processes, introducing the performance evaluation problems and difficulties in nonprofit organizations at the same time. Finding out the solutions to improve and promote the performance evaluation in nonprofit organization. The countermeasures mainly in three aspects: the government to broaden the regulations and restrictions as well as given the nonprofit organization independent or personnel management, intermediary agency should be built based on profession to promote the works of nonprofit organization and the nonprofit organization should strengthen itself. The diversity of the nonprofit organizations determines the ways 
and means for the performance evaluation of nonprofit organizations are different.

In short, the performance evaluation of the nonprofit organizations should orient to the mission to improve the organizational capacity, for the purpose of organizational strategy in combination with the specific circumstances of the nonprofit organizations to build a multi-dimensional, multi-faceted performance evaluation system.

\section{References}

[1] Robert D, Herman, David O Renz. Organization Effectiveness Research and Theory [J]. Management \& Leadership, 2008, 18(4):399-415

[2] Deng Guosheng. APC Theory of Nonprofit Organization [J]. Administration of China, 2004, (10):33-40 (In Chinese)

[3] Zhang Chengfu, Dang Xiuyun. Public Management [M]. Beijing: Press of Renmin University of China, 2001.30. (In Chinese)

[4] Vicente Pina and Lourdes Torres, Evaluating the Efficiency of Nonprofit Organizations: an Application of Data Envelopment Analysis to the Public Health Service, Financial Accountability \& Management, 1992. 8(3)

[5] Dennis L Poole, Joan Nelson, Sharon Carnahan, Evaluating Performance Measurement Systems in Nonprofit Agencies: The Program Accountability Quality Scale (PAWS) [J]. American Journal of Evaluation, 2000, 21(1): 15-30

[6] Dale A Henderson, Bruce W Chase, Benjamin M Woodson. Performance Measures for NPOs [J]. Online Publication, Journal of Accountancy, 2002, 1.

[7] Deng Guosheng. Assessment of Nonprofit Organizations [M]. Beijing: Press of Social Sciences of Academics 2001:48, 67-68 (In Chinese)

[8] Denis Johnston and Cabriel Rudney, Characteristics of Workers in Nonprofit Organizations, Monthly Labor Review. July 1987

[9] Brooks, Arthur C. Evaluating the Effectiveness of Nonprofit Fundraising, Policy Studies Journal, 2004.
[10] Dale A. Henderson, Bruce W. Chase and Benjamin M. Woodson. Performance Measures for NPOs, Online Publication, Journal of Accountancy, January 2002. 